\title{
DESIGN OF AND WITH SENSING MACHINE ELEMENTS - USING THE EXAMPLE OF A SENSING ROLLING BEARING
}

\author{
Schirra, Tobias; \\ Martin, Georg; \\ Kirchner, Eckhard
}

TU Darmstadt

\begin{abstract}
In this paper the development process of a sensing rolling bearing is presented, from which finally design rules for sensing machine elements are derived. In the first step, the requirements of the users are determined. It turns out user of sensing machine elements want to continue to use the advantage of the standardized machine elements and costs should not be incurred by redesign or complex assembly. With these requirements the development of the sensing rolling bearing is started, in which the different presented technologies are reviewed for their suitability regarding the requirements. With the selected technology measuring the electric rolling bearing impedance to estimate rolling bearing loads, a first prototype is developed by creating a functional structure of the product and focusing on the partial solution of the most relevant partial functions. This prototype is then tested with regard to its functionality. Finally, generalizable design rules for sensing machine elements are derived from the development.
\end{abstract}

Keywords: Design for X (DfX), Design practice, Industrial design

\section{Contact:}

Schirra, Tobias

TU Darmstadt

Institute for product development and machine elements

Germany

schirra@pmd.tu-darmstadt.de 


\section{INTRODUCTION}

The development towards the digitized industry 4.0 has shown that the demand for high quality data is increasing. This data is used to perform predictive maintenance or to increase productivity by monitoring the process. Both strategies of predictive maintenance and process monitoring can be illustrated by the example of the machine tool. The example of a milling machine (Stanula et al., 2020) shows that the trend is moving towards pay per stress in order to lower the hurdle of investment costs and actually pay for the wear of the machine. On the one hand, by monitoring the rolling bearing forces, the load on the machine can be determined and thus a remaining useful lifetime can be estimated. This is used for billing and for predictive maintenance. On the other hand, the knowledge about the load can be used to actually use the limits of the machines to increase productivity. Other examples for the emergence of such availability-oriented business models can be found in the printing machine and packaging machine sectors, and more generally wherever high machine availability is crucial towards economic success (Bechev et al., 2017; Slatter, 2018).

Literature (Gwosch, 2019; Martin, Schork et al., 2018; Vorwerk-Handing et al., 2020) shows that one way to capture this data is to use sensing machine elements (Martin, Vogel et al., 2018). Here the focus is especially on rolling bearings, since these are machine elements which are used in almost every application (Vogel and Kirchner, 2019). Several approaches using different technologies have been presented in the literature (Brecher et al., 2014; Brecher et al., 2019; Schirra et al., 2018; Winkelmann, 2014). The data measured with the sensing machine elements is used to perform predictive maintenance or to increase productivity by monitoring the process. The aforementioned papers either describe the classification and application of SME from a design science perspective, or details of the technical implementation from a machine element perspective. However, this research is of little help to the design practitioner whose task is to develop a new sensing machine element or to apply a sensing machine element in a machine, i.e. it gives little help for the design of and with sensing machine elements.

In this paper, we present the case study of the development of a force-measuring rolling bearing and some generalized conclusions drawn from this development process. In section 3 we describe and generalize the customer requirements found by an empirical study. In section 4 we compare different sensor technologies with respect to the requirements and describe the chosen solution. In section 5 we derive design rules that can act as a guide for future development and application of sensing machine elements.

\section{STATE OF THE ART}

In this section, the different methods already described in literature for measuring the rolling bearing load are presented.

\subsection{Displacement measurement}

In displacement measurement, the displacement between the inner and outer ring of the rolling bearing is measured (Brecher et al., 2019). This method is based on the fact that a rolling bearing load causes deformation of the raceway and rolling element in the load zone. In order to measure the distance, additional space is required in the axial direction where the sensors can be mounted, shown in Figure 1. The disadvantage of this method is that rolling bearing arrangements, especially in the application in machine tools, are designed in such a way that the rolling bearing arrangement is as stiff as possible and thus the deformation due to the load is very small (Harris, 2001). The challenge here is the measuring accuracy. In addition, influences such as the formation of the lubricant film thickness must be taken into account in the evaluation. The measurement of the displacement between the rolling bearing rings is already used in the first products (Tyrrel, 2019), which increase the axial installation space of rolling bearings. The sensor uses the inherent mechanic behaviour of the machine element, but needs an additional sensor element to convert it into an electric quantity. Therefore, it can be classified as a sensor integrating machine element in the classification of (Vorwerk-Handing et al., 2020). 


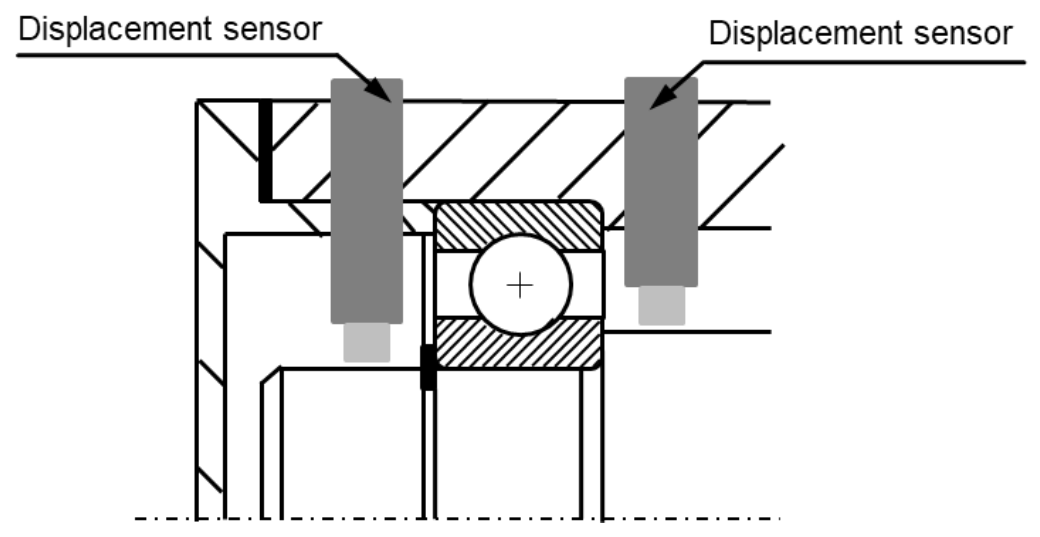

Figure 1: Measuring set-up for determining the displacement between the inner and outer ring of rolling bearings, according to (Brecher et al., 2019).

\subsection{Strain measurement}

A load applied to a rolling bearing not only leads to a compressive deformation of the outer ring and housing, but to a slight bending deformation of the outer race. Due to the high sensitivity of strain gauges, this strain can be measured in spite of its low amplitude. For strain measurement, strain gauges are manufactured onto the surface of the rolling bearing or housing. The rolling bearing loads can now be determined from the measured strains (Winkelmann, 2014). The manufacturing processes for coating the surfaces with the sensors to measure the strain are thermal, chemical and electrochemical. The surface of a rolling bearing where the strain sensors can be seen is shown in Figure 2.

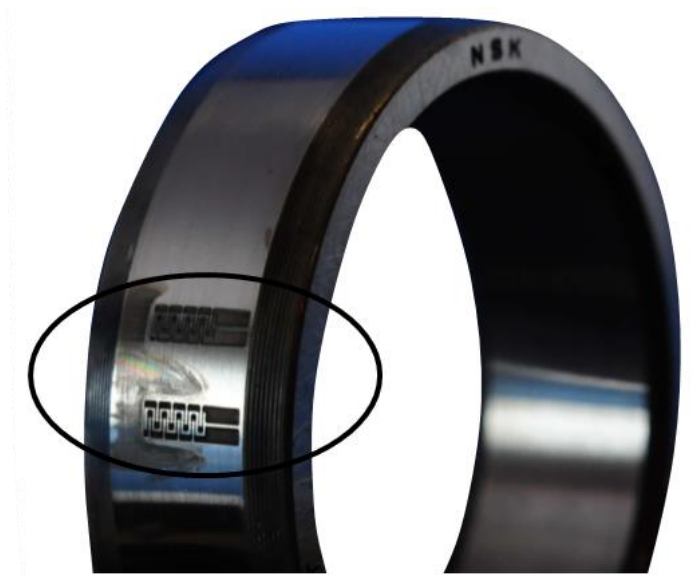

Figure 2: Rolling bearings with sensors to measure the elongation of the bearing rings (Winkelmann, 2014)

This technology is used in pedestal bearings were equipped with sensors to measure the mass flow over conveyor belts. However, the technology could not establish itself and disappeared from the market. Possible reasons could be the durability of the sensor technology or the problem that every rolling bearing has to be reworked with a coating. Similar to the displacement measurement, the sensor uses the deformation of the rolling bearing and can be classified as a sensor-integrating machine element conforming (Vorwerk-Handing et al., 2020).

\subsection{Ultrasonic measurement}

The measurement of ultrasonic surface waves is also used to determine the load on rolling bearings. Surface acoustic waves are used to determine the characteristics of a rolling bearing (Brecher et al., 2014). The waves propagate in elastic solid bodies with limited thickness. They represent a superposition between a longitudinal and a transverse wave. In a substrate of limited thickness, different propagating modes are generated, velocity of which depends on the stress in the solid and the thickness of the lubricant on the surface of the rolling element. This method can be used to determine if a rolling element in the load zone moves past the sensor and to check the lubricant film thickness. Thus, the lubricant film thickness can be determined, and using the well-known relationship between the axial load and the outer 
race ball passing frequency, the axial load can also be determined (Dahlke, 1994). The arrangement of the sensors in the rolling bearing is shown in Figure 3 and is already used in a product. Similar to the Strain and distance measurement, the sensor takes advantage of the inherent behaviour of the machine element, but needs an additional sensor to transform it into an electric quantity, and can therefore be classified as a sensor-integrating machine element conforming (Vorwerk-Handing et al., 2020).

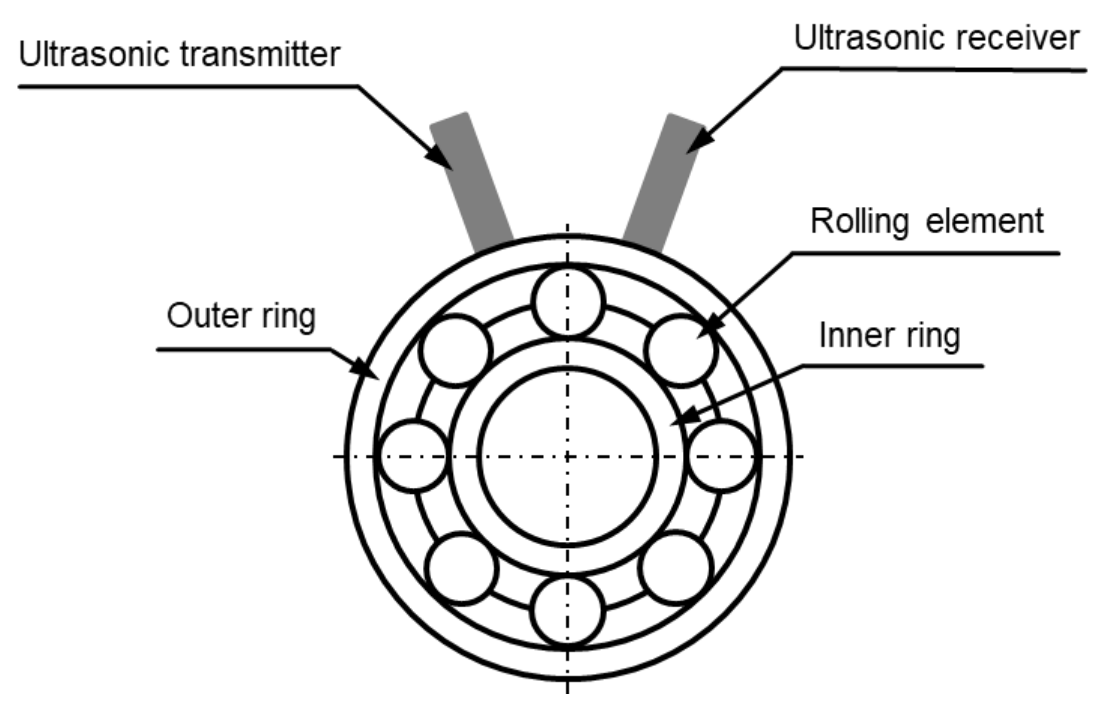

Figure 3: Schematic of the ultrasonic sensor system in the rolling bearing, according to (Brecher et al., 2014)

\subsection{Electrical impedance measurement}

For load measurement using the electrical impedance of rolling bearings, the effect is used that, under elastohydrodynamic operating conditions, the dielectric lubricant separates the surfaces of the rolling element and the outer or inner ring, respectively (Schirra et al., 2018). This setup of two conductive bodies separated by a dielectric effectively creates a measurable capacitance. In the electrical model, shown in Figure 4, each rolling contact is assumed to be a plate capacitor where the capacitance depends on the Hertzian surface as the plate area and the lubricant film thickness as the plate distance. The individual rolling contacts are interconnected via the rolling elements and rolling bearing rings. Since the lubrication film thickness depends on speed and temperature, these quantities also need to be measured. Based the measurement of speed, temperature and impedance, the load can be derived using the established relationships between these three measurands and the rolling bearing's impedance. No sensor solution based on this principle has yet appeared on the market.
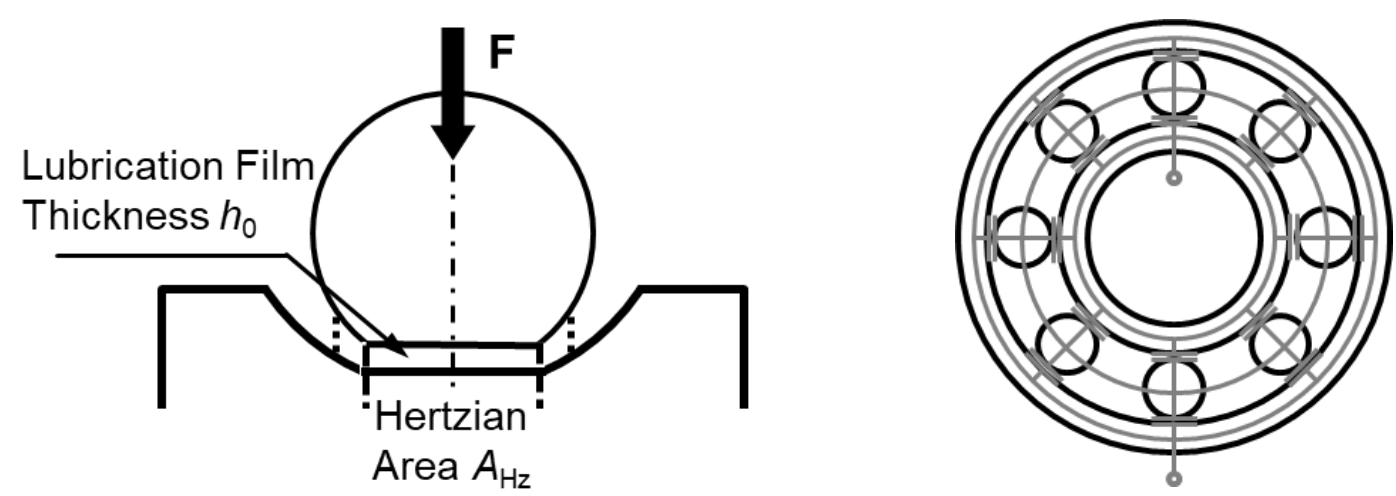

Figure 4: Electric model of a rolling contact and a rolling bearing (Martin et al., 2020)

The advantage of this technology is that there is no need to install a sensor on the rolling bearing. Instead, the inherent properties of the rolling bearing are used to measure them and derive the load, i.e. the principle directly uses the machine element's electric behavior. Therefore, this principle can be classified as a sensory utilizable machine element in the nomenclature of (Vorwerk-Handing et al., 2020). 


\section{CASE STUDY - USER REQUIREMENTS FOR SENSING ROLLING BEARINGS}

Based on the known state of the art, discussions were held with users as to why products already available on the market are not yet suitable for the respective application and what the requirements are for a rolling bearing that measures the load. In addition to the measurement functions, three requirements have emerged as central prerequisites. The users are eight engineers who have responsibility for integrating predictive maintenance in their companies and have already had contact with a technology to measure bearing forces. Based on these discussions, requirements were derived, which are described below. Non-compliance with these requirements will result in the sensing rolling bearing not being used.

The first important requirement is to avoid structural weaknesses. If the machine structure is changed in such a way that relevant deformations or weak points become apparent and a need for design change arises, the sensing rolling bearing cannot be used. In most applications, the costs resulting from the necessary design changes exceeds the possible cost savings by using the sensing rolling bearing. Therefore no economic use can be made here.

The second important requirement is to minimize the amount of redesign needed to integrate the sensing rolling bearing into the application. On the one hand, this creates the possibility to use the sensing rolling bearing also in existing machinery by retrofitting. On the other hand, the argument that high costs resulting from the redesign must not exceed the savings potential of the application is also valid here. An example are industrial gears, which have an identical, scaled design in the different power classes. This means that a modification to a gear unit in this case leads to design efforts for the entire product structure. In most cases, additional axial installation space is not available, since a change here usually leads to changes on the entire shaft, which means an enormous effort.

The third important requirement is assembly. The actual assembly process for the existing rolling bearing should not be extended. While the costs for design changes can be distributed over all machines produced and can therefore be seen as fixed costs, the assembly process must be carried out on each individual part, leading to variable costs. Therefore, special care must be taken that the costs incurred by the assembly process do not compensate for the potential benefits of the technology.

These three requirements, while derived from a specific case study, can be described in more general terms, which can be useful for other applications as well. It is clear from the central requirements that it is important for user acceptance that the design changes which the machine's product developer has to make in order to apply the sensing machine element should be as non-existent as possible and that the measuring machine elements can replace the standard solution without modification. In short, the sensing machine element is only useful in practice if its application does not cause structural weakness of the machine, few design changes are necessary and the assembly process is maintained.

\section{CASE STUDY - DEVELOPMENT OF THE SENSING ROLLER BEARING}

Based on the user requirements described in section 3, the different technologies were compared. The results can be seen in Figure 5. The measurement of the displacement only requires a hole in the unloaded area to connect the sensor with the evaluation. A major disadvantage is the additional design effort and the obstruction of the assembly process, both caused by the sensor ring next to the original bearing. In addition, the ring requires additional axial installation space, so that the sensor solution cannot replace the classic rolling bearing, but requires a significant design effort. Strain measurement also requires holes in the machine housing to contact the measuring equipment. The strain sensor technology itself, which is directly applied to the surface, does not require relevant additional space. The only thing that has to be taken into account during installation is that the strain gauges on the surface are not damaged. The measurement of ultrasonic waves does not require any additional installation space, and during installation only the sensor must be mounted in the holes provided for this purpose. These holes, however, must be located in the load zone of the rolling bearings, since the technology is based on measuring the frequency of the passing rolling elements under load. This weakening of the structure must be taken into account with design effort or premature damage may occur. 


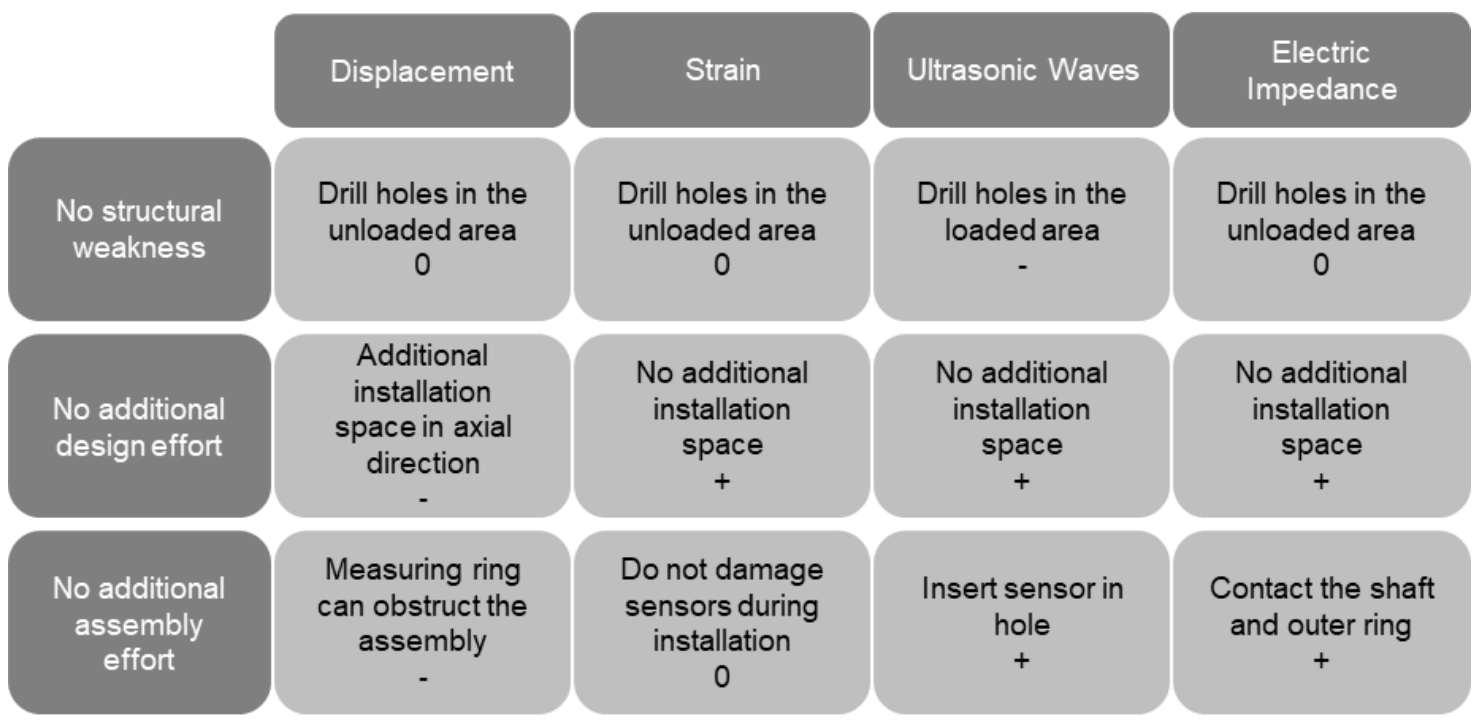

+ Technology likely to meet requirements; 0 Low risk technology does not meet requirements;

- High risk technology probably does not meet requirements

Figure 5: Comparison between technologies and user requirements

The measurement of the electrical impedance requires only hole in the unloaded area to close the electric circle to the outer ring, so there is no structural weakness. The necessary temperature sensor can be applied via the hole on the outer ring and it has been shown that the speed can be extracted from the signal (Martin et al., 2020), so that no additional components are required in the installation space relevant for the function. The contacting of the shaft requires only minimal space and can be carried out wherever there is space around the shaft, inside the machine housing or outside of it. The additional assembly requirement is limited to the contacting of the outer ring through the mentioned hole and the contacting of the shaft.

After comparing the technologies, the measurement of electrical impedance was selected to offer the greatest potential for users. This technology has the lowest risk of not meeting customer requirements for the product. In all likelihood, no additional design or assembly effort is required and there is only a small risk of structural weaknesses. The corresponding design concept has already been developed in the literature (Martin et al., 2020) and is shown in Figure 6. The concept consists of an insulating layer at the surfaces, which contact the housing. The insulation guarantees a defined current path through the rolling bearing. The inner ring or shaft is contacted by a component shown here in black on the right side of the rolling bearing beside the sensors. This component and the outer ring are connected to the impedance measuring unit to measure the electrical impedance of the rolling bearing. The rolling bearing load is then determined from the impedance, temperature and speed data. This measuring method offers the additional possibility to monitor the condition of the rolling bearing and the lubricant.

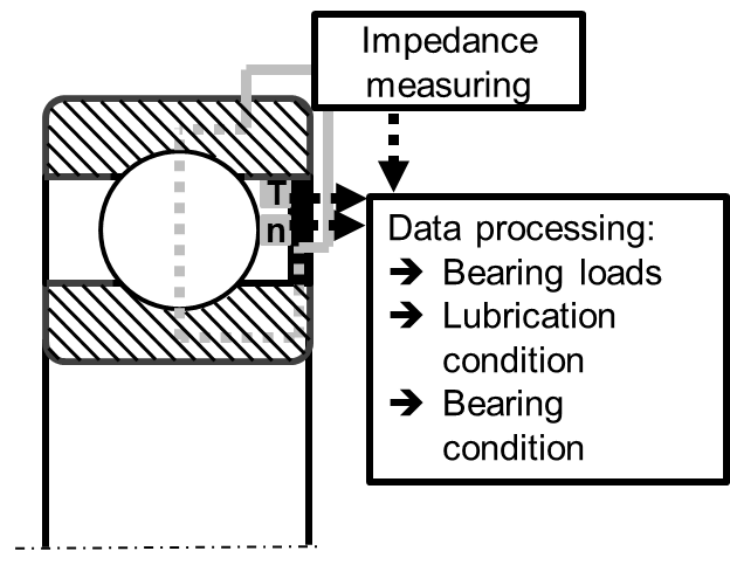

Figure 6: Concept of a sensing rolling bearing based on the measurement of the electric impedance by (Martin et al., 2020) 
The shown concept consists of partial functions, for which partial solutions to an overall solution are to be developed and implemented in a first prototype. The first partial function is the impedance measuring technique, which measures the total impedance between inner and outer ring. Other partial functions are the contact of the outer ring and of the shaft. These contacts close the electric circuit through the rolling bearing. In order to measure only the rolling bearing's impedance, independent of the surrounding structure, the rolling bearing needs to be isolated from the shaft and housing. This isolation is the fourth partial function. In addition, the measuring functions of temperature and speed are needed. Finally, the impedance, temperature and speed information is converted into a load value. The rolling bearing is part of the measuring function, as it converts the load signal into an electrical behaviour. The corresponding function representation (Kirchner, 2020) is shown in Figure 7.

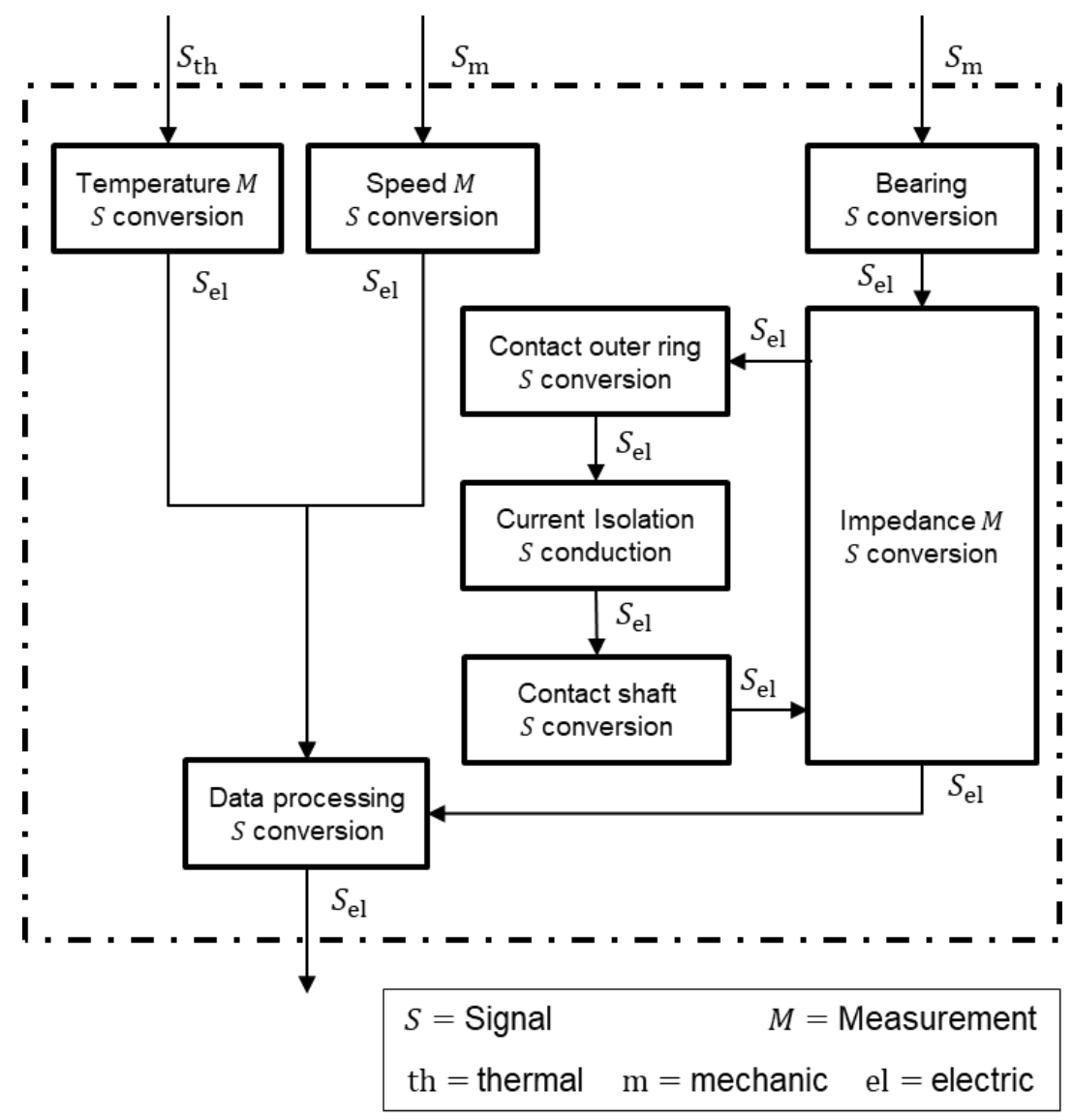

Figure 7: Functional structure of the sensor rolling bearing

A comparison of the sub-functions with the quality function deployment method has shown that the focus of technical development should be on the contacts of the outer ring and shaft, because they are decisive to meet the customer requirements "design effort" and "assembly effort". The first prototype is shown in Figure 8. The already installed rolling bearing type was used as the rolling bearing. Here the advantage is used that the technology works with any type of rolling bearing. Only a standard ceramic coating on the rolling bearing rings is used to fulfil the insulation function. The outer ring of the rolling bearing is contacted through a hole, where the temperature sensor is also mounted. The speed is derived by advanced analysis methods from the measured data. The shaft is contacted with a slip ring in the prototypical implementation and the measurement technology is mounted in a box on the housing. Thus, as a design change, only a hole on the outer ring in the unloaded zone must be made. The assembly process for the rolling bearing is not affected, only the sensor technology must be mounted in the hole and the measuring box and the slip ring on the housing. Thus, the prototype neither weakens the structure nor does it require additional design or assembly work. With these properties, it fulfills the requirements laid down in section 3. 


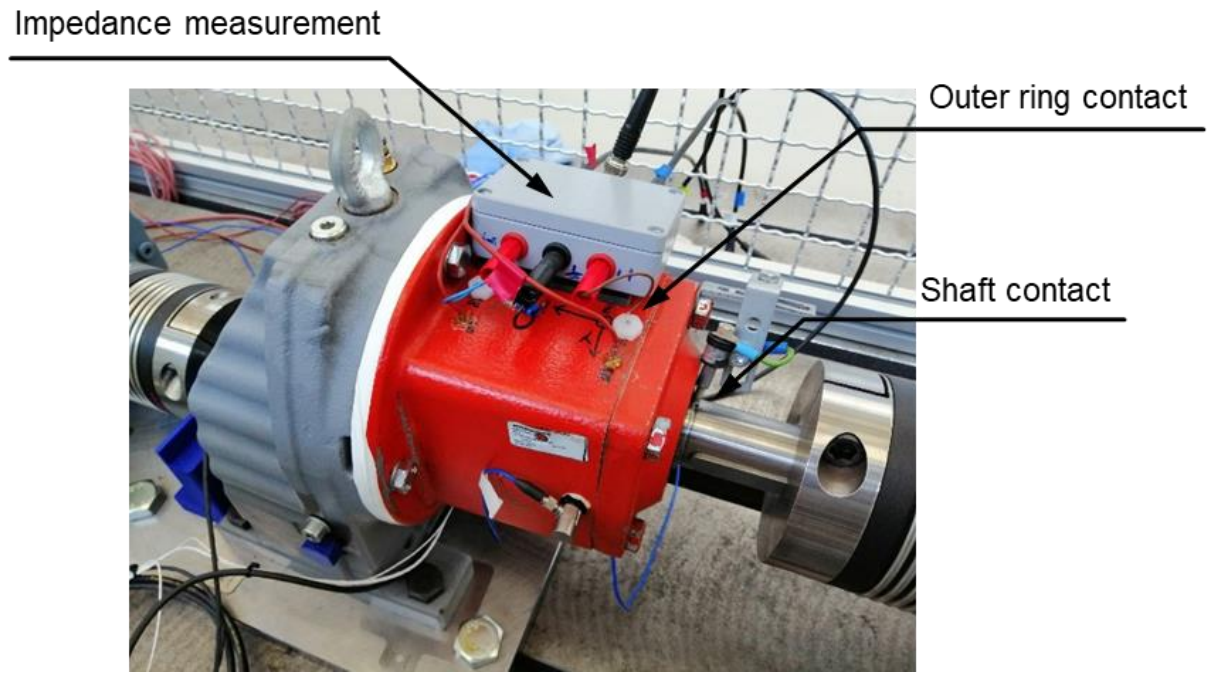

Figure 8: Prototype of the sensor rolling bearing in the industrial gearbox

During a functional test on the test bench, the transmission in which the prototype was installed is clamped between two electric motors and operated at a speed of $1350 \mathrm{~min}^{-1}$ to load the transmission with different torque levels. A temperature of $50 \mathrm{C}$ is set on the outer ring. Now different torque stages are approached, which lead to different radial loads at the sensing rolling bearing, which is installed as a floating bearing. Figure 9 shows test results, each test point is repeated six times. It turns out the individual torque steps can be differentiated. As expected, the electrical impedance decreases with increasing torque, because with increasing torque the radial load increases and the impedance decreases with increasing load (Schirra et al., 2019).

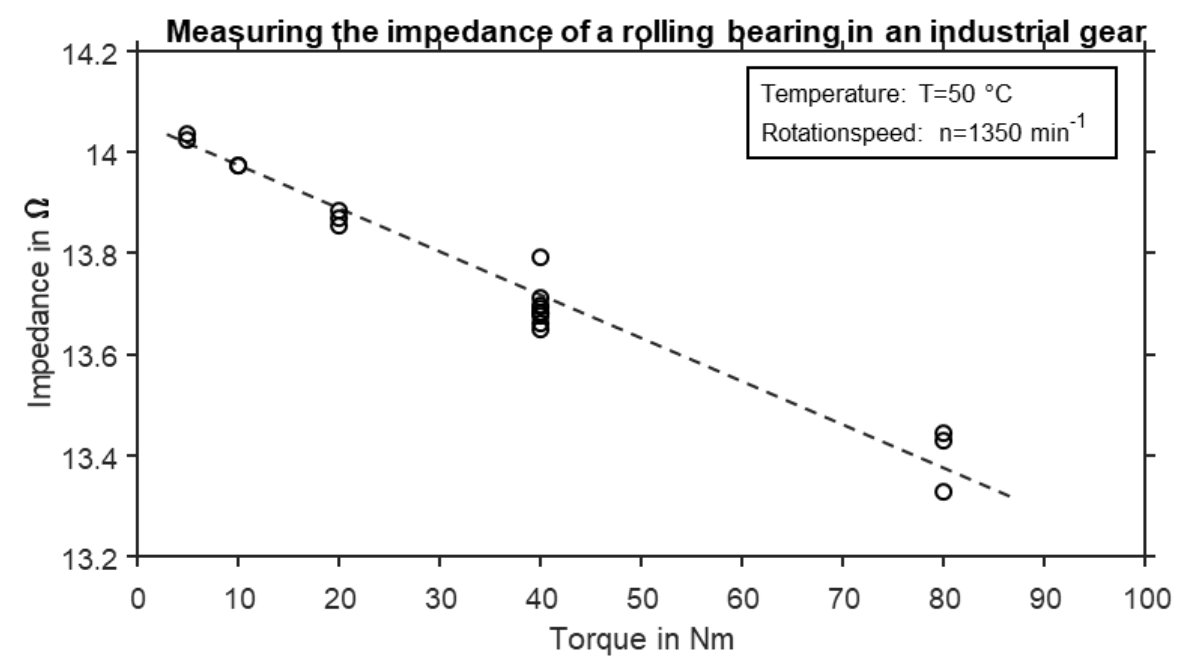

Figure 9: Measurements with the prototype of the sensor rolling bearing

\section{DERIVATION OF DESIGN RULES BASED ON THE CASE STUDY}

The results of the presented case study have an important application for the development of design rules. As was pointed out in section 3, a practically usable sensing machine element should not require any major design modification on the part of the product developer who is using the sensing machine element. The presented solution fulfils this requirement to a very high degree. For this sensing machine element, no major design changes are necessary and therefore, no design rules for "design for sensing machine elements" need to be formulated. However, significant effort has to be put into the development of the sensing machine element in order to fulfil this requirements. Therefore, some general design rules for the design of sensing machine elements are derived from the case study and presented in this section. The requirements that users place on sensing machine elements result in design rules that must be implemented to meet these requirements, the first draft of design rules for sensing machine elements 
are shown in Table 1. The avoidance of weakening the structure means that adjustments should be made only in areas which are unloaded. Structural weak points lead to failures, or force the product developer to make additional design efforts, e.g. by increasing housing wall thickness. Also in order to avoid additional design efforts, the installation space of the classical machine element should be maintained. The example in Table 1 shows drill holes outside the load zone are better suited to weaken the structure much less. Machine elements have internationally defined dimensions that are taken into account in the design of machines. An adaptation of these dimensions leads to design costs, which usually affect the entire machine. Especially the standardized interfaces, often laid down in international standards like ISO 15 for rolling bearings, should be mentioned here. If installation space is needed for additional components, e.g. for energy supply or connectivity, they should be implemented in such a way that they can be placed flexibly in unoccupied space, away from the machine element itself. The example in Table 1 shows that sensors outside the installation space of the rolling bearing require additional space, which is eliminated by mounting the sensors in the rolling bearing. The avoidance of additional assembly work can be achieved by focusing on the standardized interfaces of the machine elements. These mechanical interfaces are the key to assembly and should also remain unchanged. Additional efforts in the assembly lead to the revision of the assembly processes. In addition, the assembly expenditures are reflected directly in the manufacturing costs and cannot be reallocated to a large number of components, as it is the case with design efforts. The example in Table 1 shows, strain gauges on fitting surfaces, these lead to additional expenditure during the assembly. Mounting on other surfaces reduces the additional effort.

\section{Table 1: Design rules for sensing machine elements}

$\begin{array}{ll}\text { Design rule } & \text { Effect } \\ \text { Confine the } & \text { Limiting changes to } \\ \text { need of } & \text { unencumbered areas } \\ \text { adjustments } & \text { means there is no } \\ \text { to unloaded } & \text { effort to control } \\ \text { areas } & \text { structural weak } \\ & \text { points }\end{array}$

\section{Example from the case study $\mathrm{Bad}$}

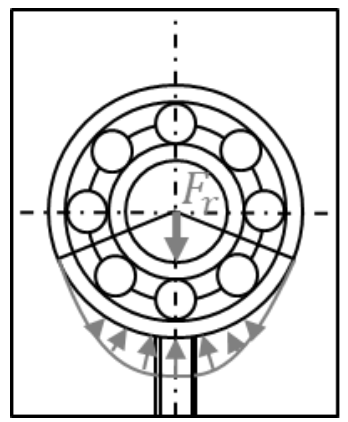

Maintain installation space mechanical interfaces
Maintaining the installation space means costs are not incurred by adapting the functionally relevant installation space

Maintaining the mechanical interfaces allows the existing assembly process to be maintained

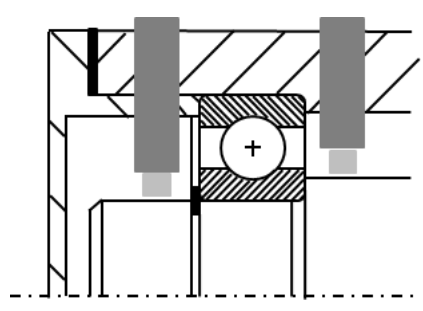

Good
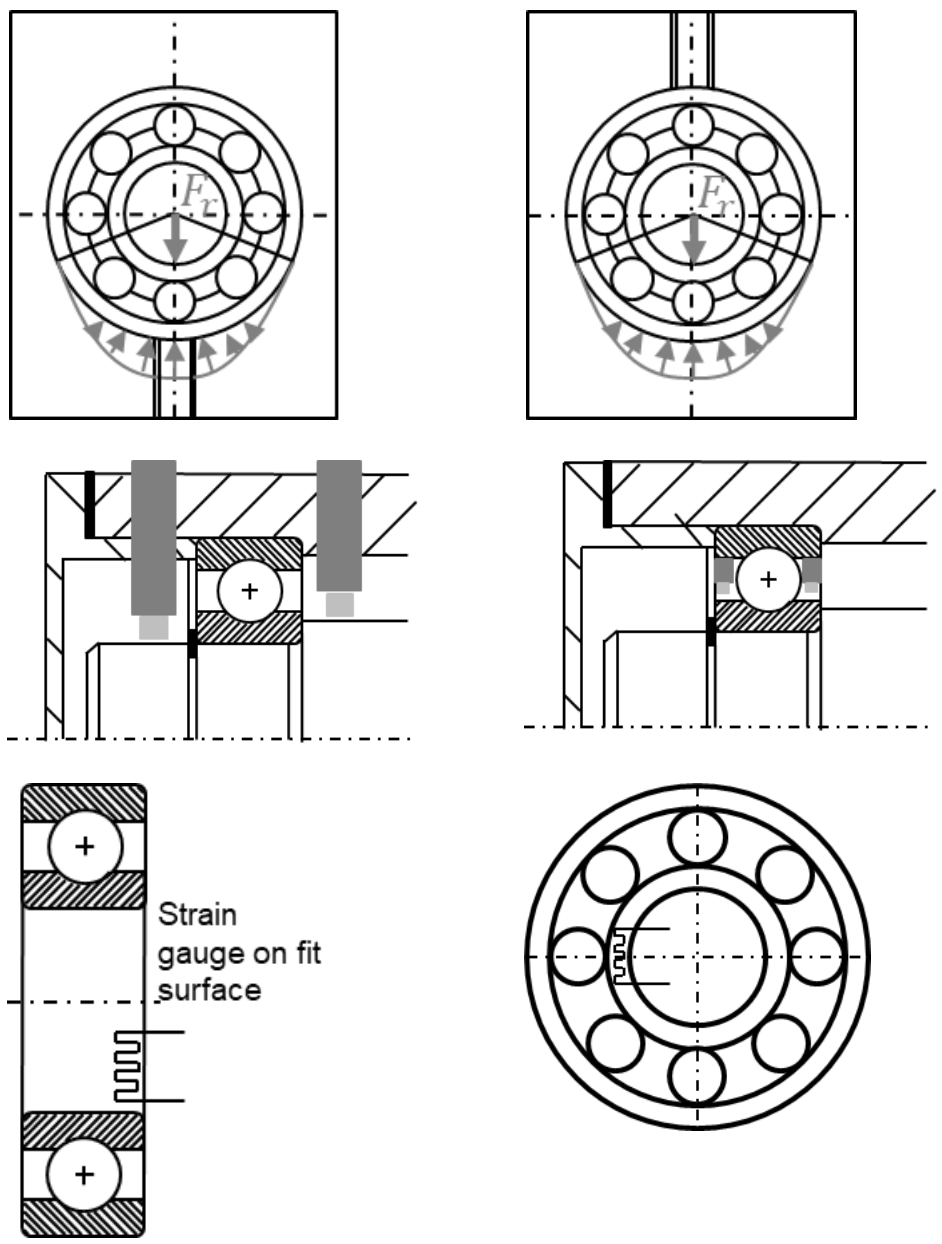

\section{CONCLUSIONS}

This paper addresses the question of requirements and design rules for the development of and with sensing machine elements. The requirements are derived by investigating the requirements of the users. 
The user is the product developer who is designing a machine that incorporates the sensing machine element, i.e. this product developer is designing with a sensing machine element. It becomes apparent that the users do not want to make any changes in their design to incorporate sensing machine elements. This means that sensing machine elements which require a "design for sensor-integrating machine elements" will not gain widespread application among users. In special applications, depending on the case-specific high saving potentials, applications are possible, but not in standard applications. This restriction imposed by the users' requirements leads to the fact that the developer of sensing machine elements has to make a large design effort himself in order to deliver a product which satisfies the requirements. The three presented design rules are the first draft of design rules that can help the designer of sensing machine elements to develop a product that fulfils the user requirements. They are derive from the presented practical example and can work as a guideline for the design effort of sensing machine elements.

\section{REFERENCES}

Bechev, D., Sauer, B., Kölsch, P., Herder, C. F., Aurich, J., Wiegel, T. and Seewig, J. (2017) 'Strategy for the diagnosis and prediction of machine failures for developing availability-oriented business models in capital goods', International Scientific Journal "Industry 4.0", vol. 2, no. 2, pp. 86-90.

Brecher, C., Falker, J. and Fey, M. (2019) 'Untersuchung des Betriebsverhaltens radial belasteter Hochgeschwindigkeitswälzlager', in 13. VDI-Fachtagung Gleit- und Wälzlagerungen, pp. 197-208.

Brecher, C., Fey, M., Brückner, C. and Falker, J. (2014) 'Überwachung des Betriebszustandes von Wälzlagern mittels akustischer Oberflächenwellen', in 17, ITG/GMA Symposium Sensors and Measuring Systems, Berlin, Germany, VDE, pp. 1-6.

Dahlke, H. (1994) Handbuch Wälzlager-Technik: Bauarten, Gestaltung, Betrieb, Braunschweig, Wiesbaden, Vieweg.

Gwosch, T. (2019) Antriebsstrangprüfstände zur Ableitung von Konstruktionszielgrößen in der Produktentwicklung handgehaltener Power-Tools, Karlsruhe, Karlsruher Institut für Technologie.

Harris, T. A. (2001) Rolling bearing analysis, 4th edn, New York, NY, Wiley.

Kirchner, E. (2020) Werkzeuge und Methoden der Produktentwicklung: Von der Idee zum erfolgreichen Produkt, Berlin, Heidelberg, Springer Berlin Heidelberg.

Martin, G., Schirra, T. and Kirchner, E. (2020) 'Experimental High Frequency Analysis of the Electric Impedance of Rolling Bearings', in Bearingworld 2020.

Martin, G., Schork, S., Vogel, S. and Kirchner, E. (2018) 'MME - Potentiale durch mechatronische Maschinenelemente', Konstruktion, vol. 70, 01-02, pp. 71-75.

Martin, G., Vogel, S. and Kirchner, E. (2018) 'Sensor Integrating Machine Elements - Key to In-Situ Measurements in mechanical Engineering’, in 23rd International Seminar on High Technology, pp. 63-75.

Schirra, T., Martin, G. and Kirchner, E. (2019) 'Untersuchung elektrischer Eigenschaften von Wälzlagern zur Entwicklung eines Sensorlagers: Analyse zum Einfluss der Last und Drehzahl auf die Wälzlagerimpedanz’, in 13. VDI-Fachtagung Gleit- und Wälzlagerungen, pp. 367-372.

Schirra, T., Martin, G., Vogel, S. and Kirchner, E. (2018) 'Ball bearings as sensors for systematical combination of load and failure monitoring', Proceedings of the DESIGN 2018 15th International Design Conference, May, 21-24, 2018, Faculty of Mechanical Engineering and Naval Architecture, University of Zagreb, Croatia; The Design Society, Glasgow, UK, pp. 3011-3022.

Slatter, R. (2018) 'Robust Magnetic Sensors for Availability-oriented Product-Service Systems', in 12th Smart Systems Integration Conference, pp. 207-214.

Stanula, P., Praetzas, C., Kohn, O., Metternich, J., Weigold, M. and Buchwald, A. (2020) “'Stress-oriented, databased payment model for machine tools"', Procedia CIRP, vol. 93, pp. 1526-1531.

Tyrrel, M. (2019) 'Sensing wear on the spindle', Production Engine Solutions.

Vogel, S. and Kirchner, E. (2019) 'Simple Integration of Sensory Functions', Proceedings of the Design Society: International Conference on Engineering Design, vol. 1, no. 1, pp. 3711-3720.

Vorwerk-Handing, G., Gwosch, T., Schork, S., Kirchner, E. and Matthiesen, S. (2020) 'Classification and examples of next generation machine elements', Forschung im Ingenieurwesen, vol. 84, no. 1, pp. $21-32$.

Winkelmann, C. H. (2014) Mikro-Elektrostrukturieren planarer und zylindrischer Oberflächen mittels strukturierter, flexibler und mehrlagiger Gegenelektroden mit integriertem fluidischen Kanal, Dissertation, Bremen, Universität Bremen. 